\title{
Evaluation of Fracture Toughness, Color Stability, and Sorption Solubility of a Fabricated Novel Glass Ionomer Nano Zirconia- Silica-Hydroxyapatite Hybrid Composite Material
}

\author{
Sami D. Aldhuwayhi $\mathbb{D}^{1}$, Arbaz Sajjad $\mathbb{D D}^{2}$, Wan Zaripah W. Bakar ${ }^{(\mathbb{D}}{ }^{3}$ \\ Dasmawati Mohamad $\left(\mathbb{0},{ }^{4}\right.$ Thirumulu P. Kannan $\left(\mathbb{1},{ }^{5}\right.$ and Imran A. Moheet $\left(\mathbb{1}{ }^{6}\right.$ \\ ${ }^{1}$ Department of Prosthodontics, College of Dentistry, Majmaah University, Al-Majmaah 11952, Saudi Arabia \\ ${ }^{2}$ Dental Materials Department, School of Dental Sciences, Universiti Sains Malaysia, Health Campus, 16150 Kubang Kerian, \\ Kota Bharu, Kelantan, Malaysia \\ ${ }^{3}$ Conservative Dentistry Unit, School of Dental Sciences, Universiti Sains Malaysia, Health Campus, 16150 Kubang Kerian, \\ Kota Bharu, Kelantan, Malaysia \\ ${ }^{4}$ Biomaterials Unit, School of Dental Sciences, Universiti Sains Malaysia, Health Campus, 16150 Kubang Kerian, Kota Bharu, \\ Kelantan, Malaysia \\ ${ }^{5}$ Human Genome Centre \& School of Dental Sciences, Universiti Sains Malaysia, Health Campus, 16150 Kubang Kerian, Kota Bharu, \\ Kelantan, Malaysia \\ ${ }^{6}$ Department of Dental Materials, Baqai Dental College, Baqai Medical University, Pakistan
}

Correspondence should be addressed to Wan Zaripah W. Bakar; wzaripah@usm.my

Received 18 December 2020; Revised 22 March 2021; Accepted 5 April 2021; Published 17 April 2021

Academic Editor: Yiqi Yang

Copyright (c) 2021 Sami D. Aldhuwayhi et al. This is an open access article distributed under the Creative Commons Attribution License, which permits unrestricted use, distribution, and reproduction in any medium, provided the original work is properly cited.

\begin{abstract}
The aim of this study was to investigate the effects of adding a nano zirconia-silica-hydroxyapatite (nanoZrO $\left.\mathrm{Z}_{2}-\mathrm{SiO}_{2}-\mathrm{HA}\right)$ composite synthesized using a one-pot sol-gel technique to a conventional glass ionomer cement (GIC), which was then characterized using X-ray diffraction (XRD). Following the characterization studies, further investigations were carried out after the addition of nano $\mathrm{ZrO}_{2}-\mathrm{SiO}_{2}-\mathrm{HA}$ to cGIC ( $\mathrm{GIC}$ nanoZrO$\left.-\mathrm{SiO}_{2}-\mathrm{HA}\right)$ at various percentages ( $5 \%$ to $\left.9 \%\right)$ to compare their fracture toughness, color stability, and sorption- solubility in relation to cGIC (Fuji IX). The XRD diffractogram indicated the presence of peaks for $\mathrm{ZrO}_{2}, \mathrm{SiO}_{2}$, and HA. The fracture toughness of GIC $5 \%$ nanoZrO $\mathrm{Z}_{2}-\mathrm{SiO}_{2}-\mathrm{HA}$ was statistically higher than that of other percentages of GIC nanoZrO $\mathrm{Zn}_{2}-\mathrm{SiO}_{2}-\mathrm{HA}$ and cGIC. The highest values recorded were fracture toughness $\left(1.35 \pm 0.15 \mathrm{MPa}^{1 / 2}\right)$, leading to an increase of $\sim 57 \%$, as compared to cGIC. Overall, the color change $(\Delta E)$ values for GIC $5 \%$ nano $\mathrm{Zr}$-Si-HA group were lower than those of cGIC over a one-month period and were between slight and perceptible. In addition, GIC $5 \%$ nanoZ $\mathrm{ZrO}_{2}-\mathrm{SiO}_{2}-\mathrm{HA}$ recorded lower sorption values $\left(23.64 \pm 2.3 \mu \mathrm{gmm}^{-3}\right)$ as compared to cGIC $\left(36.28 \pm 2.6 \mu \mathrm{gmm}^{-3}\right)$ and higher solubility $\left(66.46 \pm 2.4 \mu \mathrm{gmm}^{-3}\right)$ as compared to cGIC $\left(56.76 \pm 1.6 \mu \mathrm{gmm}^{-3}\right)$. The addition of nanoZ $\mathrm{rO}_{2}-\mathrm{SiO}_{2}-\mathrm{HA}$ to cGIC significantly enhanced its physicomechanical properties. Based on the results of our study, GIC nanoZrO $\mathrm{riO}_{2}-\mathrm{SA}$ has the potential to be suggested as a restorative dental material with diverse applications ranging from cavity restoration, core build-up, and as a luting material.
\end{abstract}

\section{Introduction}

A decline in the use of traditional silver amalgam restorations due to the fear of mercury toxicity and tooth and gingival discoloration has led to increased interest in tooth-colored restorative materials such as GIC and composite resins. Glass ionomer cements were first introduced to dentistry in the late 1960s and have proven to be useful in restorative dentistry. Glass ionomers as a system which is polyelectrolytic and aqueous are east to manipulate, bond to tooth at an ionic 
TABle 1: Powder composition of nanoZrO $\mathrm{rr}_{2}-\mathrm{SiO}_{2}-\mathrm{HA}$.

\begin{tabular}{lcccc}
\hline Composite & Mass of HA (g) & Mass of $\mathrm{SiO}_{2}(\mathrm{~g})$ & Mass of $\mathrm{ZrO}_{2}(\mathrm{~g})$ & Powder composition \\
\hline $\mathrm{NanoZrO}_{2}-\mathrm{SiO}_{2}$-HA & 10.04 & 1.356 & 3.79 & $66.75 \% \mathrm{HA}^{-} 8.25 \% \mathrm{SiO}_{2}, 25 \% \mathrm{ZrO}_{2}$ \\
\hline
\end{tabular}

level, and exhibit fluoride (F) release and recharge, a low coefficient of thermal expansion, and decent aesthetics [1]. They are also biocompatible with pulp, gingival, and bone tissues. However, in the clinical environment, their use has become limited owing to inferior mechanical properties such as low flexural strength and fracture toughness (FT) [2-5]. In addition, a relatively high opacity, moisture susceptibility during early setting phase makes these materials less desirable [6-9]. Therefore, GICs have become restricted to restoring low stress-bearing areas such as proximal and axial wall defects [10].

In order to overcome the drawbacks of GIC, additions to the glass powder such as metallic oxides, strontium, and barium were attempted but these did not have a significant effect on the mechanical properties of GICs since they lacked the ability to increase the cross-linking within the glass matrix [11-13]. Recent research has proven that incorporation of nanoceramics such as hydroxyapatite (HA), silica $\left(\mathrm{SiO}_{2}\right)$, and zirconia $\left(\mathrm{ZrO}_{2}\right)$ produced via various soft chemistry processes capable of creating nanoscale particles has the potential to improve the properties of GICs [14-17].

Recently at the biomaterials lab at our dental school, a novel nanoZrO $\mathrm{Zr}_{2}-\mathrm{SiO}_{2}-\mathrm{HA}$ composite was synthesized by one-pot synthesis and incorporated into conventional GIC (cGIC). The effect induced by the phenomenon of adding nanoZrO $\mathrm{CO}_{2}-\mathrm{SiO}_{2}-\mathrm{HA}$ to the cGIC on its physicomechanical properties was analyzed. The addition of nanoZ $\mathrm{ZO}_{2}-\mathrm{SiO}_{2}$ $\mathrm{HA}$ produced surprising improvements in the compressive strength, flexural strength, and F release of cGIC [18-20]. FTIR characterization of the GIC nanoZrO $\mathrm{Zr}_{2}-\mathrm{SiO}_{2}-\mathrm{HA}$ revealed that there was chemical interaction between the polymeric phase of GIC and the nanopowder [19]. However, concerns regarding the FT, color stability (CS), and sorptionsolubility of the nanoZrO ${ }_{2}-\mathrm{SiO}_{2}-\mathrm{HA}$ when added to GIC need to be addressed. Therefore, the aim of this study was to evaluate the FT, CS, and the sorp-sol of the GIC nano $\mathrm{ZrO}_{2}-\mathrm{SiO}_{2}-\mathrm{HA}$ hybrid material.

\section{Methods}

Fuji IX Universal (GC Corp., Japan) was selected as the control material for our study as it is a widely used cGIC in dentistry. Fuji IX has also been recommended as the material of choice for atraumatic restorative treatment (ART) by the World Health Organization (WHO). For manipulation and ease, it is dispensed in the form of an ionomeric powder and liquid polyacid. The various other chemicals and reagents used for the synthesis of nanoZrO $\mathrm{Z}_{2}-\mathrm{SiO}_{2}-\mathrm{HA}$ were of high purity and analytical grade, which were purchased commercially. First, the nano HA was synthesized using the sol-gel technique described by Rahman et al. (2017) [21]. Calcium hydroxide (>98\%)
(Merck Serono Pvt. Australia) and phosphoric acid (>99\%) (Sigma-Aldrich Co. LLC, USA) was the primary sources for calcium and phosphorus. A quantity of $7.408 \mathrm{~g}$ of calcium hydroxide dissolved into $100 \mathrm{ml}$ of distilled water, $4.104 \mathrm{ml}$ of phosphoric acid, and $5 \mathrm{ml}$ of TEOS (Merck Serono Pvt. Australia) and 25\% $\mathrm{ZrO}_{2}$ (US Research Nanomaterials, USA) were used to make the sol. The white viscous sol was washed with copious absolute ethanol (HmbG Chemicals, Germany) and was conditioned for $1 \mathrm{~h}$ in a $-80^{\circ} \mathrm{C}$ freezer and finally freeze-dried under vacuum for $24 \mathrm{~h}$. The resultant powder was manually ground for 10 mins using a mortar and immediately calcined at $600^{\circ} \mathrm{C}$ for $1 \mathrm{~h}$ in a furnace oven. The quantity of nano $\mathrm{ZrO}_{2}$ and nano $\mathrm{SiO}_{2}-\mathrm{HA}$ in the nanopowder composite are presented in Table 1.

2.1. XRD Characterization. The qualitative analysis of the synthesized nanopowder was carried out XRD (D2 PHASER, Bruker Technologies, USA). The nanopowder was placed on the double-sided carbon-based tape and placed inside the XRD machine. The analysis was performed at a rate of $0.02 \mathrm{~min}^{-1}$. CuK $\alpha$ radiation was used with a current of $10 \mathrm{~mA}$ operating at $30 \mathrm{kV}$.

2.2. Fracture Toughness Evaluation. Fracture toughness was determined according to the method outlined in ASTM specification E-399-90 for single-edge V-notch beam (SEVNB) samples loaded in transverse bending. Fifty knife-edge notch samples ( $n=10$ /group) with dimensions of $25 \mathrm{~mm} \times 2.5$ $\mathrm{mm} \times 5 \mathrm{~mm}$ were prepared in a split metal mold. The nanoZ $\mathrm{ZrO}_{2}-\mathrm{SiO}_{2}-\mathrm{HA}$ powder was added at various percentages $(3 \%, 5 \%, 7 \%$, and $9 \%)$ by volume, into the cGIC to prepare a total of four experimental groups. The powder of GIC nanoZrO $\mathrm{ZO}_{2}-\mathrm{SiO}_{2}-\mathrm{HA}$ together with liquid was then mixed using spatulation technique on the mixing pad with an agate spatula for $30 \mathrm{sec}$ in a clockwise direction. The cement mix was condensed into the mold that was then pressed between two polyester strip and glass plates under load for $10 \mathrm{~min}$. The beam-shaped samples were carefully removed from and stored at $37^{\circ} \mathrm{C}$ in $100 \%$ humidity for $50 \mathrm{~min}$ then in distilled water for $23 \mathrm{~h}$. A notch with $0.5 \mathrm{~mm}$ width and $2.5 \mathrm{~mm}$ depth was prepared using a low-speed diamond band saw (Exakt 300, Exakt Tech. Inc., USA). The notch tip was refined and sharpened with the help of a razor blade in a gentle back and forth motion [22].

A three-point bending test was done in a universal testing machine (AG-X plus $20 \mathrm{KN}$, Shimadzu, Japan) at a crosshead speed of $0.5 \mathrm{~mm} / \mathrm{min}$. The moment a sample cracks was identified by a sudden drop in load during testing. All the fractured parts were visually inspected to verify that the fracture plane passed through the notch in the center of the sample and that it was perpendicular to the horizontal plane. 
Fracture toughness, $K_{1 c}\left(\mathrm{MPa} \cdot \mathrm{m}^{1 / 2}\right)$, was calculated from the following equation:

$$
K_{1 c}=\frac{\left(P_{Q} S\right)}{\left(B W^{3 / 2}\right)} \cdot F\left(\frac{a}{W}\right)
$$

where $P q$ is the peak load $(\mathrm{kN}), S$ is the span $(\mathrm{cm}), B$ is the sample thickness $(\mathrm{cm}), W$ is the sample width $(\mathrm{cm})$, and $a$ is the crack length $(\mathrm{cm}) . F(a / W)$ is a function of $a / W$ and is calculated as: $F(a / W)=3(a / W)^{1 / 2} \times 1: 99-(a / W)(1-a /$ $W)(1-a / W) \times\left(2.25-3.93 a / W+2.7 \mathrm{a}^{2} / W^{2} / 2(1+2 a / W)\right.$ $1-a / W)^{3 / 2}$.

2.3. Color Stability Evaluation. The results of FT found that GIC 5\% nanoZ $\mathrm{rO}_{2}-\mathrm{SiO}_{2}-\mathrm{HA}$ exhibited superior properties compared to CGIC and other groups. Therefore, from here forth for all the other testing GIC 5\% nanoZ $\mathrm{ZO}_{2}-\mathrm{SiO}_{2}-\mathrm{HA}$ was evaluated. A total of 20 samples ( $n=10$ /group) were prepared, measuring $5 \mathrm{~mm}$ in diameter $\times 2 \mathrm{~mm}$ in thickness. The powder and liquid were mixed and loaded in a PTFE split mold. The mold was then covered with polyester strips and pressed with a glass plate. After $15 \mathrm{~min}$, samples were removed from the mold, and a baseline color measurement was taken with a portable spectrophotometer with a measurement range of $400 \sim 700 \mathrm{~nm}$ (VITA Easyshade $^{\circledR}$ Advance 4.0, VITA Zahnfabrik, Germany). During the test, period samples were stored at $37^{\circ} \mathrm{C}$ and $100 \%$ relative humidity in airtight containers. The CIE (Commission internationale de l'éclairage) $\mathrm{L} *, \mathrm{a} *, \mathrm{~b} *$ values of the GIC $5 \%$ nano $\mathrm{ZrO}_{2}-\mathrm{SiO}_{2}-\mathrm{HA}$ experimental group were compared with the cGIC group to evaluate the color change from baseline to the final measurement.

The CIELAB coordinates of each sample were measured at the following time intervals: baseline, day one, day seven, day 14, and day 28. This time duration was selected in order to detect any apparent change in the color of the samples. The spectrophotometer was calibrated before each measurement session using the white calibration tile supplied by the manufacturer. Three readings were taken at the center of each sample with a standardized white background below. The samples were not allowed to dehydrate and were kept moist throughout the experiment. They were blotted dry just prior to measurement. The colorimetric values were calculated using the equation below, where $\Delta E$ is the color change, $\Delta L *$ is the change in value, and $\Delta a *$ and $\Delta b *$ represent the changes in the chromatic coordinates.

$$
\Delta E=\left[(\Delta L *)^{2}+(\Delta a *)^{2}+(\Delta b *)^{2}\right]^{1 / 2}
$$

To emphasize and provide a reference guideline, the results of color changes $(\Delta E)$ values were presented along with National Bureau of Standards (NBS) values by applying the following formula: $\mathrm{NBS}=\Delta E \times 0.92$.

2.4. Sorption-Solubility Evaluation. Sorption-solubility samples were prepared using PTFE molds with an inner dimension of $10 \times 2 \mathrm{~mm}$. Twenty disc-shaped samples were prepared as previously described in color stability sample

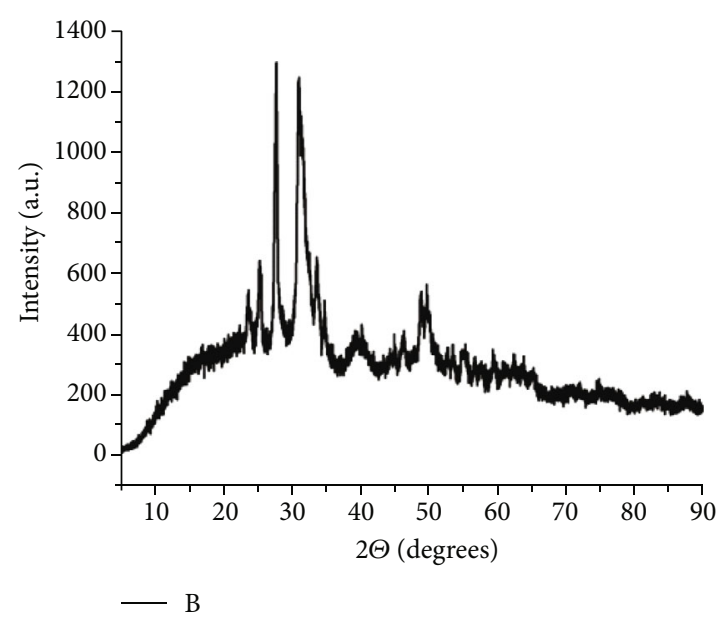

Figure 1: XRD of nanoZrO $\mathrm{Xr}_{2}-\mathrm{SiO}_{2}$-HA powder.

preparation. Samples were stored in a silica gel desiccator set at $37 \pm 1^{\circ} \mathrm{C}$ for $22 \mathrm{~h}$. Following which, samples were transferred to a second desiccator at $25 \pm 1^{\circ} \mathrm{C}$ for $2 \mathrm{~h}$. The samples were then weighed in a digital analytical balance machine with a resolution of $0.1 \mathrm{mg}$ (Mettler Toledo ${ }^{\mathrm{TM}}$, Fisher Scientific $^{\mathrm{TM}}$, USA) every single day at the same hour of the day, and this cycle was repeated until a constant mass was acquired $\left(m_{1}\right)$. The mass was considered constant if it showed mass variations of up to $0.1 \mathrm{mg}$ from the previous day. After recording $m_{1}$, the samples were stored in artificial saliva for 7 days at $37 \pm 1^{\circ} \mathrm{C}$ after which the samples were removed, blot dried with absorbent paper, and weighed for the second time $\left(m_{2}\right)$. Following this, the samples were stored in the desiccators as detailed in the storage protocol used for $m_{1}$, until a constant mass was achieved $\left(m_{3}\right)$. The volume $(V)$ of each sample was calculated in $\mathrm{mm}^{3}$. Water sorption $\left(W_{s p}\right)$ and solubility $\left(W_{s l}\right)$ values for each sample were calculated using the following equations given below, where $m$ is mass and $V$ is sample volume and the mean of sorption- solubility was recorded in $\mu \mathrm{gmm}^{-3}$.

$$
\begin{aligned}
& W_{s p}=\frac{m_{2}-m_{3}}{V}, \\
& W_{s l}=\frac{m_{1}-m_{3}}{V} .
\end{aligned}
$$

2.5. Statistical Analysis. For FT, the data was statistically analyzed using IBM SPSS version 23 (IBM Corp., USA). One-way analysis of variance (ANOVA) coupled with a post hoc Tukey HSD multiple range test was used to determine a significant difference $(\alpha \leq 0.05)$. Whereas for CS repeated measure analysis of variance (ANOVA), with a Bonferroni correction was employed and for sorption solubility, independent sample $t$-test (two-tailed) was used.

\section{Results}

3.1. XRD Characterization. The diffraction patterns indicated the presence of peaks of $\mathrm{ZrO}_{2}, \mathrm{SiO}_{2}$, and HA (Figure 1). The first peak at $\sim 23^{\circ}$ belongs to 120 plane of $\mathrm{SiO}_{2}$ and another 
TABLE 2: The mean fracture toughness of cGIC and GIC nanoZrO $\mathrm{H}_{2}-\mathrm{SiO}_{2}-\mathrm{HA}$ using one-way ANOVA.

\begin{tabular}{|c|c|c|c|c|c|c|}
\hline Groups & Sample size $(n)$ & 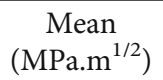 & Std. deviation & Std. error & $\begin{array}{l}\text { Minimum } \\
\left(\mathrm{MPa}^{1 / 2} \mathrm{~m}^{1 / 2}\right.\end{array}$ & $\begin{array}{l}\text { Maximum } \\
\left(\mathrm{MPa}_{\mathrm{m}} \mathrm{m}^{1 / 2}\right)\end{array}$ \\
\hline cGIC & 10 & $0.780^{\mathrm{b}, \mathrm{c}, \mathrm{d}, \mathrm{e}}$ & 0.205 & 0.065 & 0.524 & 1.152 \\
\hline GIC 3\%nanoZrO $2-\mathrm{SiO}_{2}-\mathrm{HA}$ & 10 & $1.164^{\mathrm{a}}$ & 0.112 & 0.035 & 0.980 & 1.340 \\
\hline GIC 5\% nanoZrO ${ }_{2}-\mathrm{SiO}_{2}-\mathrm{HA}$ & 10 & $1.354^{\mathrm{a}, \mathrm{d}, \mathrm{e}}$ & 0.157 & 0.049 & 1.168 & 1.650 \\
\hline GIC 7\% nanoZrOH $-\mathrm{SiO}_{2}-\mathrm{HA}$ & 10 & $1.099^{\mathrm{a}, \mathrm{c}}$ & 0.132 & 0.041 & 0.877 & 1.241 \\
\hline GIC 9\%nanoZrOH $-\mathrm{SiO}_{2}-\mathrm{HA}$ & 10 & $1.052^{\mathrm{a}, \mathrm{c}}$ & 0.147 & 0.046 & 0.745 & 1.245 \\
\hline
\end{tabular}

$*$ In each column, a different superscript alphabet indicates a significant difference between each group $(p \leq 0.05)(\mathrm{cGIC}=\mathrm{a}, 3 \%=\mathrm{b}, 5 \%=c, 7 \%=\mathrm{d}$, and $9 \%=\mathrm{e})$.

peak at $\sim 25^{\circ}$ corresponds to 002 plane of HA and 011 plane of $\mathrm{SiO}_{2}$. Similarly, another peak at $\sim 28^{\circ}$ also represents 102 plane of $\mathrm{HA}$ and 111 plane of $\mathrm{SiO}_{2}$. These findings are in accordance to those of previously published literature [14, $23]$. The XRD displayed a very strong peak at $\sim 32^{\circ}$ that corresponded to the 112 plane of $\mathrm{HA} ; 012$ plane of $\mathrm{SiO}_{2}$ and 011 plane of $\mathrm{ZrO}_{2}$. Next, a shoulder peak at $\sim 34^{\circ}$ was due to the 300 plane of $\mathrm{HA}$, and 002 plane of $\mathrm{ZrO}_{2}$ indicated the presence of HA that was not as predominant as pure HA crystal and could be attributed to the silicon doping effect. Other smaller peaks at $\sim 40^{\circ}, 46,49$, and 55 correspond to $\mathrm{HA}$ (212), $\mathrm{SiO}_{2}$ (113), $\mathrm{ZrO}_{2}$ (020), and HA (312), respectively. Peaks through $\sim 59-60^{\circ}$ are those of 121 planes of $\mathrm{ZrO}_{2}$ and finally peak at $\sim 65^{\circ}$ represent 104 and 132 plane of $\mathrm{HA}$ and $\mathrm{SiO}_{2}$, respectively. These findings are similar to the characterization studies published previously $[14,23$, 24]. The particle size was calculated by taking $32^{\circ}$ peak as the reference peak and full with half maxima (FWHM) as 0.4 using the Scherrer's equation (Particle size $=0.94 * \lambda / \beta$ $\operatorname{Cos} \theta)$, where $\lambda$ is the wavelength of $\operatorname{Cuk} \alpha=0.15148 \mathrm{~nm}$, $\beta=0.4,2 \theta=32^{\circ}$, and $\theta=16^{\circ}$ converted into radians and was found to be $21.62 \mathrm{~mm}$.

The phase purity and information of various chemical species have been characterized by XRD, and nanocrystalline nature has been ascertained by XRD. All of the peaks in XRD patterns have a good match with the standard of $\mathrm{HA}, \mathrm{ZrO}_{2}$, and $\mathrm{SiO}_{2}$ phase in terms of position of the lines. A decrease in the crystallinity of $\mathrm{HA}$ at $\sim 34^{\circ}$ in the nanopowder composite indicates the presence of amorphous $\mathrm{SiO}_{2}$. The diffraction peaks centred at $\sim 32^{\circ}(011)$ and $\sim 34^{\circ}(002)$ are characteristics of the tetragonal $\mathrm{ZrO}_{2}$. These findings suggest that a nanoZ $\mathrm{ZO}_{2}-\mathrm{SiO}_{2}-\mathrm{HA}$ composite was synthesized by the onepot sol-gel method.

3.2. Fracture Toughness. The results of the FT test after 1-day immersion in distilled water for cGIC (Fuji IX) and four GIC nanoZ $\mathrm{rO}_{2}-\mathrm{SiO}_{2}-\mathrm{HA}$ experimental groups are shown in Table 2. The FT of cGIC was the lowest recorded among the groups (Figure 2 ) with a mean $K_{\text {IC }}$ value of $0.78 \mathrm{MPa}^{1 / 2}$ $( \pm 0.20)$. The maximum recorded $K_{I C}$ value of $1.65 \mathrm{MPa}^{1 / 2}$ was for GIC $5 \%$ nanoZ $\mathrm{ZrO}_{2}-\mathrm{SiO}_{2}-\mathrm{HA}$ with a mean $K_{I C}$ value of $1.35 \mathrm{MPa}^{1 / 2}( \pm 0.15)$. There was a significant statistical difference between FT values of GIC $5 \%$ nanoZrO $\mathrm{Zr}_{2}-\mathrm{SiO}_{2}$ $\mathrm{HA}$ and all the other groups except GIC 3\% nanoZ $\mathrm{rO}_{2}$ $\mathrm{SiO}_{2}$-HA with $(p=0.061)$.

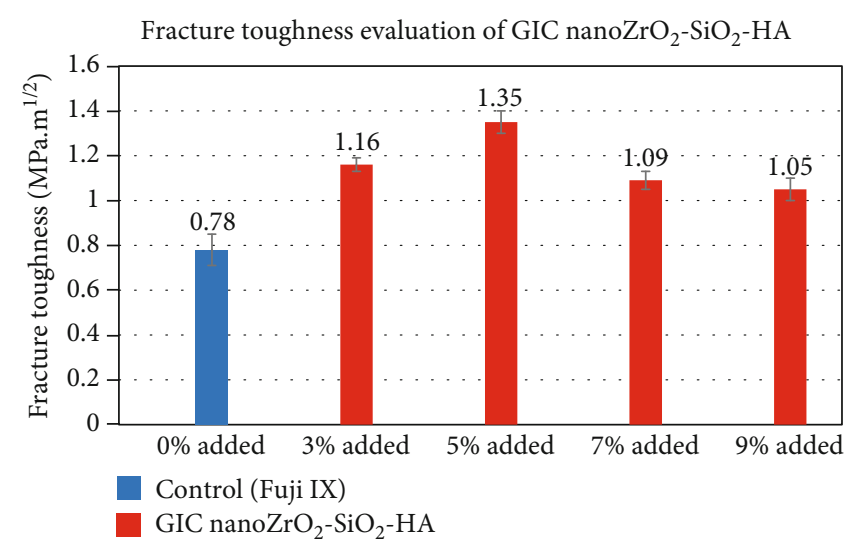

FIgURE 2: Fracture toughness evaluation of GIC nanoZrO $\mathrm{Zr}_{2}-\mathrm{SiO}_{2}-$ HA.

3.3. Color Stability. Results are showed in Tables 3 and 4 which reflect the color change $(\Delta E)$ between the various time intervals and between day 1 (baseline) and the different time intervals, respectively. There was a statistically significant difference between the day 1 to day 7 and day 14 to day $28 \Delta E$ values (Table 3) for cGIC $\left(\Delta E_{1}=2.40\right.$ and $\left.\Delta E_{3}=2.72\right)$ and GIC $5 \%$ nanoZrO $\mathrm{Zr}_{2}-\mathrm{SiO}_{2}-\mathrm{HA}\left(\Delta E_{1}=3.26\right.$ and $\left.\Delta E_{3}=1.32\right)$. However, $\Delta E_{2}$ and $\Delta E_{3}$ for GIC $5 \%$ nanoZrO $\mathrm{rO}_{2}-\mathrm{SiO}_{2}-\mathrm{HA}$ are much lower as compared to the cGIC group (Figure 3 ) which implies that the color of GIC 5\% nanoZ $\mathrm{ZO}_{2}-\mathrm{SiO}_{2}-\mathrm{HA}$ became more stable over time and did not change. Table 4 shows a statistically significant difference between the day 1 and day $28 \Delta E$ values for cGIC $\left(\Delta E_{6}=3.56\right)$ and GIC $5 \%$ nano $\mathrm{ZrO}_{2}-\mathrm{SiO}_{2}-\mathrm{HA}\left(\Delta E_{6}=2.75\right)$ which is also depicted graphically in Figure 4 . Also, the NBS unit for the cGIC group corresponding to $\Delta E_{6}$ was 3.2 indicative of appreciable color change. Whereas the NBS units for GIC $5 \%$ nanoZ $\mathrm{rO}_{2}$ $\mathrm{SiO}_{2}-\mathrm{HA}$ were between 2.0 and 3.0 and were indicative of only perceptible color change.

3.4. Sorption- Solubility. GIC $5 \%$ nano $\mathrm{ZrO}_{2}-\mathrm{SiO}_{2}-\mathrm{HA}$ recorded higher values for solubility but lesser values for sorption when compared with cGIC (Figure 5). Results reported for solubility value of GIC $5 \%$ nanoZ $\mathrm{rO}_{2}-\mathrm{SiO}_{2}$ HA $\left(66.46 \pm 2.4 \mu \mathrm{gmm}^{-3}\right)$ was higher than cGIC $\left(56.76 \pm 1.6 \mu \mathrm{gmm}^{-3}\right)$ which could explain the higher 
TABLE 3: Color change $(\Delta E)$ between the various time intervals using repeated-measures ANOVA.

\begin{tabular}{|c|c|c|c|c|c|c|c|c|}
\hline \multirow[t]{2}{*}{ Time interval } & \multirow{2}{*}{$\begin{array}{c}\text { Sample size } \\
\text { ( } n \text { /group) }\end{array}$} & \multicolumn{2}{|c|}{ cGIC } & \multicolumn{2}{|c|}{$\begin{array}{c}\text { GIC 5\% nanoZrO }{ }_{2}-\mathrm{SiO}_{2^{-}} \\
\mathrm{HA}\end{array}$} & \multirow{2}{*}{$\begin{array}{c}\text { Sig. } \\
(p \text { value })\end{array}$} & \multirow{2}{*}{$\begin{array}{l}\text { Std. } \\
\text { error }\end{array}$} & \multirow{2}{*}{$\begin{array}{l}\text { 95\% confidence } \\
\text { interval }\end{array}$} \\
\hline & & Mean $(\Delta E)$ & NBS units & Mean $(\Delta E)$ & NBS units & & & \\
\hline Day 1-day $7\left(\Delta E_{1}\right)$ & & $2.40 *$ & 2.2 & $3.26 *$ & 2.9 & 0.025 & 0.352 & 2.743 \\
\hline Day 7-day $14\left(\Delta E_{2}\right)$ & 10 & 2.19 & 2.0 & 1.09 & 1.0 & 0.061 & 0.550 & 0.276 \\
\hline Day 14-day $28\left(\Delta E_{3}\right)$ & & $2.72 *$ & 2.5 & $1.32 *$ & 1.2 & 0.006 & 0.443 & 0.671 \\
\hline
\end{tabular}

*The mean difference is significant at $p \leq 0.05$ level.

TABLE 4: Color change $(\Delta E)$ between day one (baseline) and other time intervals using repeated-measures ANOVA.

\begin{tabular}{|c|c|c|c|c|c|c|c|c|}
\hline \multirow[t]{2}{*}{ Time interval } & \multirow{2}{*}{$\begin{array}{c}\text { Sample size } \\
\text { (n/group) }\end{array}$} & \multicolumn{2}{|c|}{ cGIC } & \multicolumn{2}{|c|}{$\begin{array}{c}\text { GIC 5\% nanoZrO }{ }_{2}-\mathrm{SiO}_{2}- \\
\mathrm{HA}\end{array}$} & \multirow{2}{*}{$\begin{array}{c}\text { Sig. } \\
\text { ( } p \text { value })\end{array}$} & \multirow{2}{*}{$\begin{array}{l}\text { Std. } \\
\text { error }\end{array}$} & \multirow{2}{*}{$\begin{array}{l}95 \% \text { confidence } \\
\text { interval }\end{array}$} \\
\hline & & Mean $(\Delta E)$ & NBS units & Mean $(\Delta E)$ & NBS units & & & \\
\hline Day $1-$ day $7\left(\Delta E_{4}\right)$ & & $2.40 *$ & 2.2 & $3.26 *$ & 2.9 & 0.025 & 0.352 & 2.743 \\
\hline Day 1-day $14\left(\Delta E_{5}\right)$ & 10 & 2.61 & 2.4 & 2.55 & 2.3 & 0.876 & 0.352 & 2.036 \\
\hline Day 1-day $28\left(\Delta E_{6}\right)$ & & $3.56 *$ & 3.2 & $2.75 *$ & 2.5 & 0.033 & 0.353 & 2.226 \\
\hline
\end{tabular}

*The mean difference is significant at $p \leq 0.05$ level.

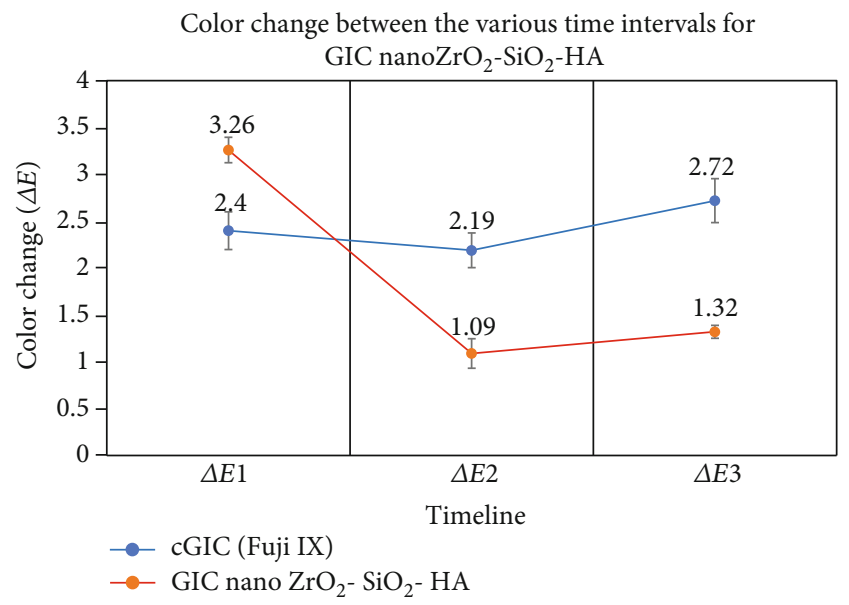

Figure 3: Color change $(\Delta E)$ evaluation between various time intervals for GIC nanoZrO $\mathrm{riO}_{2}-\mathrm{HA} . * \Delta E_{1}$ (day 1-day 7), $\Delta E_{2}$ (day 7-day 14), and $\Delta E_{3}$ (day 14-day 28).

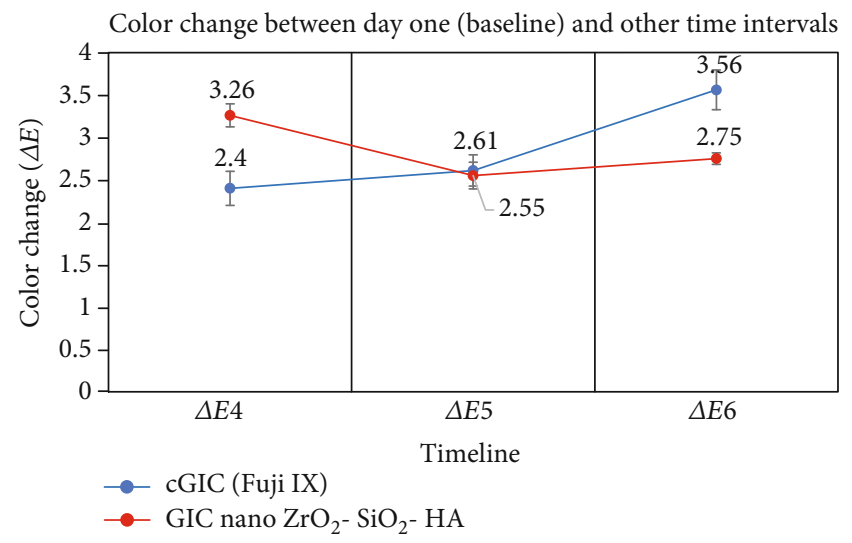

FIGURE 4: Color change evaluation between baseline and other time intervals for GIC nanoZrO $\mathrm{rO}_{2}-\mathrm{SiO}_{2}-\mathrm{HA} . * \Delta E_{1}$ (day 1-day 7), $\Delta E_{2}$ (day 7-day 14 ), and $\Delta E_{3}$ (day 14-day 28).

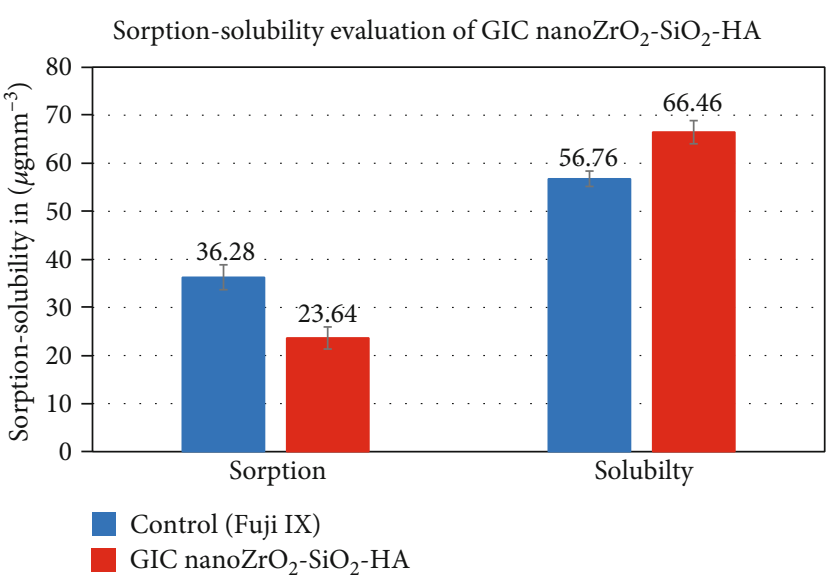

FIGURE 5: Graphical representation of sorption- solubility between GIC 5\% nanoZrO ${ }_{2}-\mathrm{SiO}_{2}$-HA and cGIC.

initial $\mathrm{F}^{-}$burst observed in our previous study [18] and also by other researchers [25], and it was found to be statistically significant (Table 5). Whereas the sorption of GIC 5\% nanoZrO $\mathrm{Zr}_{2}-\mathrm{SiO}_{2}-\mathrm{HA}\left(23.64 \pm 2.3 \mu \mathrm{gmm}^{-3}\right)$ was significantly lower than that of cGIC $\left(36.28 \pm 2.6 \mu \mathrm{gmm}^{-3}\right)$ which is an appreciable attribute as higher sorption can adversely affect the mechanical properties and color stability of the material.

\section{Discussion}

The most common causes of failure of GICs were related to fractures and wear out. Several studies have inferred that FT measurement should be considered the single most useful predictor of a material's clinical performance over other parameters presently used for evaluation. Fracture toughness is the instantaneous stress condition $\left(K_{C}\right.$ value $)$ at the initiation of the crack propagation and $K_{I C}$ (plane-strain fracture 
TABLE 5: Mean sorption- solubility for experimental groups using independent $t$-test.

\begin{tabular}{|c|c|c|c|c|c|}
\hline \multirow{2}{*}{ Groups } & \multirow{2}{*}{ Sample size $(n)$} & \multicolumn{4}{|c|}{ Sol-sorption $\left(\mu \mathrm{gmm}^{-3}\right)$} \\
\hline & & Sorption & $p$ value & Solubility & $p$ value \\
\hline cGIC & 10 & $36.28 \pm 2.6$ & \multirow{2}{*}{$0.004 *$} & $56.76 \pm 1.6$ & \multirow{2}{*}{$0.002 *$} \\
\hline GIC 5\% nanoZrO ${ }_{2}-\mathrm{SiO}_{2}-\mathrm{HA}$ & 10 & $23.64 \pm 2.3$ & & $66.46 \pm 2.4$ & \\
\hline
\end{tabular}

*Indicates significant difference between cGIC and GIC $5 \%$ nanoZrO ${ }_{2}-\mathrm{SiO}_{2}-\mathrm{HA}(p \leq 0.05)$.

toughness) in particular is an essential parameter that represents mode I type of fracture opening [26-28].

There was a partial linear correlation between the FT values and the $\%$ volume addition of nanoZrO $\mathrm{Zr}_{2}-\mathrm{SiO}_{2}-\mathrm{HA}$ to the GIC up to $5 \%$ following which any further addition of nanoZrO ${ }_{2}-\mathrm{SiO}_{2}-\mathrm{HA}$ to the GIC led to a FT decrease. These observations are in accordance with the findings of a couple of other studies in which the researchers evaluated the effect of glass fibres on the FT of GIC [29,30]. This could be due to overcrowding of filler particles, which may interfere with the polysalt bridge formation within the GIC. In general, all the GIC nanoZrO $\mathrm{Zr}_{2}-\mathrm{SiO}_{2}-\mathrm{HA}$ experimental groups had higher FT values than the cGIC group. This is probably due to the toughening effect of $\mathrm{ZrO}_{2}$ and the additive effect of HA. The homogeneous incorporation of nanoparticles in the glass component further reinforces the structural integrity of the GIC for high load tolerance and lasting durability [31-33].

Color stability is critical to the long-term success of any aesthetic restoration. The highest recorded $\Delta E$ was observed between day 1 and day 7 time interval $\left(\Delta E_{1}=3.26\right)$ for GIC $5 \%$ nanoZrO ${ }_{2}-\mathrm{SiO}_{2}-\mathrm{HA}$. This finding agrees with another study, where the authors reported similar observations [34]. However, after the $\Delta E_{1}$ time interval, $\Delta E$ values for GIC $5 \%$ nanoZ $\mathrm{ZrO}_{2}-\mathrm{SiO}_{2}-\mathrm{HA}$ were $<1.40$ and remained stable for the duration of the study. It can be hypothesized that the nanoZrO ${ }_{2}-\mathrm{SiO}_{2}-\mathrm{HA}$ particles fill the void between the glass particles, improving the packing density and prevent the possibility of phase separation during setting of the material, thereby improving the CS of cGIC. Since a $\Delta E$ value of up to 3.3 is considered to be clinically acceptable in dentistry, it can be concluded that the color of GIC $5 \%$ nanoZrO $\mathrm{Z}_{2}-\mathrm{SiO}_{2}-\mathrm{HA}$ was stable $[35,36]$. Overall, the $\Delta E$ values for GIC $5 \%$ nanoZrO $\mathrm{Zr}_{2}-\mathrm{SiO}_{2}-\mathrm{HA}$ group were lower than those of the cGIC group. The evaluation of visual perception of color change determination based on the NBS unit system was also done, which dictates that values of 0.5 to 1.5 are considered slight, values between 1.5 and 3 are perceptible, and values $>3$ are interpreted as appreciable color change $[37,38]$. The color change between various time intervals shows that the NBS units for GIC $5 \%$ nanoZrO $\mathrm{HO}_{2}-\mathrm{SiO}_{2}-$ HA group were between 1.0 and $<3.0$ and generally were lower than those of the cGIC group which were between 2.0 and 3.5. Therefore, according to NBS system, the color change for GIC 5\% nanoZrO ${ }_{2}-\mathrm{SiO}_{2}-\mathrm{HA}$ was between slight and perceptible.

In the current study, water sorption values for GIC 5\% nanoZrO $\mathrm{Zr}_{2}-\mathrm{SiO}_{2}$-HA $\left(23.64 \pm 2.3 \mu \mathrm{gmm}^{-3}\right)$ were significantly lower than cGIC $\left(36.28 \pm 2.6 \mu \mathrm{gmm}^{-3}\right)$. This is an encouraging finding as sorbed water acts as a plasticizer and can reduce the mechanical properties of GIC. Also, increased water sorption usually decreases the color stability of GIC as water-soluble stains can enter the glass matrix [25, 39]. Therefore, it can be assumed that the GIC $5 \%$ nanoZrO ${ }_{2}^{-}$ $\mathrm{SiO}_{2}$-HA will continue to display improved mechanical strength and color stability in vivo. The low water sorption could be the result of the nanoZrO filling the spaces between the micron-sized glass particles of cGIC and optimum filler content resulting in a dense network structure. However, an increase in solubility was demonstrated by GIC $5 \%$ nanoZrO $\mathrm{Zr}_{2}-\mathrm{SiO}_{2}$ - $\mathrm{HA}$ as compared to cGIC and could be due to an improved $\mathrm{F}$ ion release [18]. This is because the $\mathrm{F}$ releasing capacity of restorative materials is related to their ability to support diffusion without allowing excessive water sorption.

\section{Conclusion}

Within the limitations of this study, certain conclusions can be agreed upon and they are as follows: (a) XRD characterization studies revealed that nanoZrO $\mathrm{Zr}_{2}-\mathrm{SiO}_{2}-\mathrm{HA}$ was properly synthesized and homogenously incorporated into the cGIC, (b) The GIC 5\%nanoZrO ${ }_{2}-\mathrm{SiO}_{2}-\mathrm{HA}$ exhibited significantly higher fracture toughness when compared to cGIC and other experimental groups, and (c) the GIC $5 \%$ nanoZ $\mathrm{rO}_{2}-\mathrm{SiO}_{2}-\mathrm{HA}$ exhibited a statistically significant improvement in color stability over cGIC. Also, GIC 5\% nanoZ $\mathrm{ZO}_{2}-\mathrm{SiO}_{2}-\mathrm{HA}$ exhibited a significantly lower water sorption but higher solubility than cGIC. Based on the above findings, the GIC nanoZrO $\mathrm{Zr}_{2}-\mathrm{SiO}_{2}-\mathrm{HA}$ can be recommended for wider application such as in aesthetic areas for restoring class $\mathrm{V}$ cavities, for restoring posterior teeth in stressbearing areas, as a core build-up material and as an improved substitute for atraumatic restorative therapy.

\section{Data Availability}

The data used to support the findings of this study are available from the corresponding author upon request.

\section{Conflicts of Interest}

The authors disclose that there is no conflict of interest regarding the publication of this manuscript.

\section{Acknowledgments}

The authors would like to thank the deanship of scientific research at Majmaah University for support (Project No. 
R-2021-69). The authors would like to show sincere appreciation to the School of Dental Sciences, Universiti Sains Malaysia (USM) for providing the lab facility to conduct this study, which was part of a $\mathrm{PhD}$ thesis. The abstract for this can be accessed at Repository@USM, open access repository of USM research and publication. This research study was financially supported by Universiti Sains Malaysia under Research University Grant Scheme No. RUI 1001/PPSG/812164.

\section{References}

[1] M. A. Naasan and T. F. Watson, "Conventional glass ionomers as posterior restorations. A status report for the American Journal of Dentistry," American Journal of Dentistry, vol. 11, no. 1, pp. 36-45, 1998.

[2] A. Wilson, "A new translucent cement for dentistry. the glass ionomer cement," British Dental Journal, vol. 132, no. 4, pp. 133-135, 1972.

[3] A. Oliva, F. Della Ragione, A. Salerno et al., "Biocompatibility studies on glass ionomer cements by primary cultures of human osteoblasts," Biomaterials, vol. 17, no. 13, pp. 13511356, 1996.

[4] G. J. Mount, An Atlas of Glass Ionomer Cements : A Clinician's Guide, Martin Dunitz Ltd, United Kingdom, 3rd edition, 2002.

[5] N. Six, J. J. Lasfargues, and M. Goldberg, "In vivo study of the pulp reaction to Fuji IX, a glass ionomer cement," Journal of Dentistry, vol. 28, no. 6, pp. 413-422, 2000.

[6] A. D. Wilson and B. E. Kent, "The glass-ionomer cement, a new translucent dental filling material," Journal of Applied Chemistry and Biotechnology, vol. 21, p. 313, 1971.

[7] S. Gladys, B. Van Meerbeek, M. Braem, P. Lambrechts, and G. Vanherle, "Comparative physico-mechanical characterization of new hybrid restorative materials with conventional glass-ionomer and resin composite restorative materials," Journal of Dental Research, vol. 76, no. 4, pp. 883-894, 1997.

[8] T. P. Croll and J. W. Nicholson, "Glass ionomer cements in pediatric dentistry: review of the literature," Pediatric Dentistry, vol. 24, no. 5, pp. 423-429, 2002.

[9] A. Wilson, D, McLean JW: Glass-Ionomer Cement, Quientessence Publishing Co, Chicago, Illinois, 1st edition, 1988.

[10] H. F. Albers, "Glass ionomers," in Tooth-Colored Restoratives: Principles and Techniques, pp. 43-47, BC Decker Inc, Hamilton, ON, 9th edition, 2002.

[11] S. Deb and J. W. Nicholson, "The effect of strontium oxide in glass-ionomer cements," Journal of Materials Science: Materials in Medicine, vol. 10, no. 8, pp. 471-474, 1999.

[12] K. Hurrell-Gillingham, I. M. Reaney, I. M. Brook, and P. V. Hatton, "Novel $\mathrm{Fe}<$ sub $>2</$ sub $>\mathrm{O}<$ sub $>3</$ sub $>$-containing glass ionomer cements: glass characterisation," Key Engineering Materials, vol. 284-286, pp. 799-802, 2005.

[13] A. Sajjad, W. Z. W. Bakar, D. Mohamad, and T. Kannan, "Various recent reinforcement phase incorporations and modifications in glass ionomer powder compositions: a comprehensive review," Journal of International Oral Health, vol. 10, no. 4, p. 161, 2018.

[14] R. Ahmad Shiekh, I. Ab Rahman, S. M. Masudi, and N. Luddin, "Modification of glass ionomer cement by incorporating hydroxyapatite-silica nano-powder composite: sol-gel synthesis and characterization," Ceramics International, vol. 40, no. 2, pp. 3165-3170, 2014.

[15] A. Moshaverinia, S. Ansari, M. Moshaverinia, N. Roohpour, J. A. Darr, and I. Rehman, "Effects of incorporation of hydroxyapatite and fluoroapatite nanobioceramics into conventional glass ionomer cements (GIC)," Acta Biomaterialia, vol. 4, no. 2, pp. 432-440, 2008.

[16] R. A. S. Alatawi, N. H. Elsayed, and W. S. Mohamed, "Influence of hydroxyapatite nanoparticles on the properties of glass ionomer cement," Journal of Materials Research and Technology, vol. 8, no. 1, pp. 344-349, 2019.

[17] A. J. Noori and F. A. Kareem, "Setting time, mechanical and adhesive properties of magnesium oxide nanoparticles modified glass-ionomer cement," Journal of Materials Research and Technology, vol. 9, no. 2, pp. 1809-1818, 2020.

[18] A. Sajjad, W. Z. W. Bakar, D. Mohamad, and T. P. Kannan, "Characterization and efficacy of fluoride elusion of a novel glass ionomer nano zirconia silica hydroxyapatite hybrid material," Fluoride, vol. 52, no. 4, 2019.

[19] A. Sajjad, W. Z. W. Bakar, D. Mohamad, and T. P. Kannan, "Characterization and enhancement of physico-mechanical properties of glass ionomer cement by incorporating a novel nano zirconia silica hydroxyapatite composite synthesized via sol-gel," AIMS Materials Science, vol. 6, no. 5, pp. 730-747, 2019.

[20] A. Sajjad, W. Z. Wan Bakar, I. Ab Rahman, D. Mohamad, and T. P. Kannan, "OSC26: characterization and physico-chemical evaluation of a novel glass ionomer nanozirconia- silicahydroxyapatite hybrid material," Journal of Indian Prosthodontic Society, vol. 18, pp. S18-S19, 2018.

[21] I. A. Rahman, N. A. M. Ghazali, W. Z. W. Bakar, and S. M. Masudi, "Modification of glass ionomer cement by incorporating nanozirconia-hydroxyapatite-silica nano-powder composite by the one-pot technique for hardness and aesthetics improvement," Ceramics International, vol. 43, no. 16, pp. 13247-13253, 2017.

[22] P. Triwatana, P. Srinuan, and K. Suputtamongkol, "Comparison of two fracture toughness testing methods using a glassinfiltrated and a zirconia dental ceramic," The Journal of Advanced Prosthodontics, vol. 5, no. 1, pp. 36-43, 2013.

[23] I. A. Moheet, N. Luddin, I. Ab Rahman, S. M. Masudi, T. P. Kannan, and N. R. N. A. Ghani, "Evaluation of mechanical properties and bond strength of nano-hydroxyapatite-silica added glass ionomer cement," Ceramics International, vol. 44, no. 8, pp. 9899-9906, 2018.

[24] F. Barandehfard, M. Kianpour Rad, A. Hosseinnia et al., "The addition of synthesized hydroxyapatite and fluorapatite nanoparticles to a glass-ionomer cement for dental restoration and its effects on mechanical properties," Ceramics International, vol. 42, no. 15, pp. 17866-17875, 2016.

[25] N. Gonulol, S. Ozer, and E. Sen Tunc, "Water sorption, solubility, and color stability of giomer restoratives," Journal of Esthetic and Restorative Dentistry, vol. 27, no. 5, pp. 300-306, 2015.

[26] G. Lewis, "Predictors of clinical wear of restorative dental composite materials," Bio-medical Materials and Engineering, vol. 3, no. 3, pp. 167-174, 1993.

[27] T. Yamaga, Y. Sato, Y. Akagawa, M. Taira, K. Wakasa, and M. Yamaki, "Hardness and fracture toughness of four commercial visible light-cured composite resin veneering materials," Journal of Oral Rehabilitation, vol. 22, no. 12, pp. 857-863, 1995. 
[28] M. Fani, S. Farmani, and R. Bagheri, "Fracture toughness of resin composites under different modes and media: review of articles," Journal of Dental Biomaterials, vol. 2, no. 3, pp. 7382, 2015.

[29] S. Garoushi, P. Vallittu, and L. Lassila, "Hollow glass fibers in reinforcing glass ionomer cements," Dental Materials, vol. 33, no. 2, pp. e86-e93, 2017.

[30] W. A. Higg, P. Lucksanasombool, R. J. Higgs, and M. V. Swain, "Evaluating acrylic and glass-ionomer cement strength using the biaxial flexure test," Biomaterials, vol. 22, no. 12, pp. 1583-1590, 2001.

[31] Y. W. Gu, A. U. Yap, P. Cheang, and K. A. Khor, "Effects of incorporation of $\mathrm{HA} / \mathrm{ZrO}_{2}$ into glass ionomer cement (GIC)," Biomaterials, vol. 26, no. 7, pp. 713-720, 2005.

[32] Z. H. Ahmad, S. Anil, S. H. Bhandi, E. P. Chalisserry, M. Almuhaiza, and A. M. AlZailai, "Study of the mechanical properties of the novel zirconia-reinforced glass ionomer cement," The Journal of Contemporary Dental Practice, vol. 17, no. 5, pp. 394-398, 2016.

[33] R. Hickel and J. Manhart, "Longevity of restorations in posterior teeth and reasons for failure," Journal of Adhesive Dentistry, vol. 3, no. 1, 2001.

[34] A. Prabhakar, K. Pattanshetti, and S. Sugandhan, "A comparative study of color stability and fluoride release from glass ionomer cements combined with chlorhexidine," International Journal of Clinical Pediatric Dentistry, vol. 6, no. 1, pp. 26-29, 2013.

[35] I. E. Ruyter, K. Nilner, and B. Möller, "Color stability of dental composite resin materials for crown and bridge veneers," Dental Materials, vol. 3, no. 5, pp. 246-251, 1987.

[36] A. Vichi, M. Ferrari, and C. L. Davidson, "Color and opacity variations in three different resin-based composite products after water aging," Dental Materials, vol. 20, no. 6, pp. 530534,2004

[37] J. L. Shotwell, M. E. Razzoog, and A. Koran, "Color stability of long-term soft denture liners," The Journal of Prosthetic Dentistry, vol. 68, no. 5, pp. 836-838, 1992.

[38] S. Canay and M. C. Cehreli, "The effect of current bleaching agents on the color of light-polymerized composites in vitro," The Journal of Prosthetic Dentistry, vol. 89, no. 5, pp. 474478, 2003.

[39] D. F. Cefaly, E. B. Franco, R. F. Mondelli, P. A. Francisconi, and M. F. Navarro, "Diametral tensile strength and water sorption of glass-ionomer cements used in Atraumatic Restorative Treatment," Journal of Applied Oral Science, vol. 11, no. 2, pp. 96-101, 2003. 